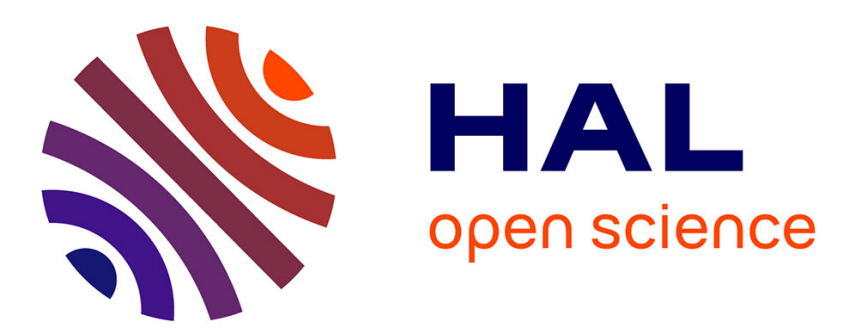

\title{
Of autophagy and in vivo pancreatic carcinogenesis: The p53 status matters!
}

Nicolas Jonckheere, Audrey Vincent, Isabelle Van Seuningen

\section{To cite this version:}

Nicolas Jonckheere, Audrey Vincent, Isabelle Van Seuningen. Of autophagy and in vivo pancreatic carcinogenesis: The p53 status matters!. Clinics and Research in Hepatology and Gastroenterology, 2014, 38 (4), pp.423-425. 10.1016/j.clinre.2014.04.009 . inserm-02341594

\section{HAL Id: inserm-02341594 https://www.hal.inserm.fr/inserm-02341594}

Submitted on 31 Oct 2019

HAL is a multi-disciplinary open access archive for the deposit and dissemination of scientific research documents, whether they are published or not. The documents may come from teaching and research institutions in France or abroad, or from public or private research centers.
L'archive ouverte pluridisciplinaire $\mathbf{H A L}$, est destinée au dépôt et à la diffusion de documents scientifiques de niveau recherche, publiés ou non, émanant des établissements d'enseignement et de recherche français ou étrangers, des laboratoires publics ou privés. 
Jonckheere, Vincent \& Van Seuningen

\section{Of autophagy and in vivo pancreatic carcinogenesis: the p53 status matters!}

1 Inserm, UMR837, Jean Pierre Aubert Research Center, Team \#5 “Mucins, epithelial differentiation and carcinogenesis", rue Polonovski, 59045 Lille Cedex, France

2 Université Lille Nord de France, 1 Place de Verdun, 59045 Lille cedex, France

3 Centre Hospitalier Régional et Universitaire de Lille, Place de Verdun, 59037 Lille cedex, France.

Corresponding author: Dr Nicolas Jonckheere, Inserm UMR837/JPARC, rue Polonovski, 59045 Lille Cedex, France, Phone: +33 3202988 50, Fax: +33 320538562

E-Mail: nicolas.jonckheere@inserm.fr

Conflict of interest

Authors declare no conflict of interest 
Jonckheere, Vincent \& Van Seuningen

\section{Summary:}

Autophagy is a lysosomal recycling process essential for tissue or cell homeostasis. The role of autophagy in cancer is complex with either tumor suppressive or pro-carcinogenesis activities. This question has been addressed by Kevin Ryan's laboratory by using Kras-driven genetic engineering mouse models in order to decipher the involvement of essential Atg5/7 autophagy genes and p53 status in pancreatic homeostasis and carcinogenetic progression. The authors show that combined loss of autophagy and p53 dramatically promotes progression from early PanIN lesions toward adenocarcinoma and alters the cellular metabolism with an enrichment of anabolic pathway that can fuel the tumor growth.

\section{Comment on:}

Rosenfeldt, MT, O'Prey, J, Morton, JP, Nixon, C, MacKay, G, Mrowinska, A, Au, A, Rai, TS, Zheng, L, Ridgway, R, Adams, PD, Anderson, KI, Gottlieb, E, Sansom, OJ \& Ryan, KM (2013) p53 status determines the role of autophagy in pancreatic tumour development. Nature 504, 296-300.

\footnotetext{
Autophagy is a lysosomal catabolic pathway used to degrade and recycle components of the cytoplasm (organelles and macromolecules). This cellular process is essential for survival, differentiation, development, and homeostasis (Levine and Kroemer, 2008). Autophagy occurs when cells need to generate intracellular nutrients and energy. Among genes that are essential for the execution of autophagy, Atg5 and Atg7 are key elements involved in the vesicle elongation forming the phagosome.
}

The role of autophagy in cancer is complex. Reports indicate that autophagy promotes either tumor suppressive or pro-carcinogenesis activities. Notably, the in vivo involvement of autophagy in 
Jonckheere, Vincent \& Van Seuningen

pancreatic carcinogenesis remains to be elucidated. This question has been addressed by the findings of Kevin Ryan's laboratory. In the 2013 December issue of Nature, The authors use genetic engineered mouse models (preclinical pancreatic cancer mouse model Pdx1-Cre; LstopL-K-ras ${ }^{\text {G12D }}$; $\mathrm{p} 53^{-/}$and conditional invalidation of $A \operatorname{tg} 5^{\text {flox/flox }}$ or $A \operatorname{tg} 7^{\text {flox/flox }}$ ) to decipher the involvement of essential autophagy genes in pancreatic homeostasis and carcinogenetic progression (Rosenfeldt et al., 2013).

First, Rosenfeldt et al demonstrate that the mosaic losses of Atg5 and Atg7 lead to the pancreas destruction independently of Kras and reduce the overall survival of mice. Both Atg5- and Atg7invalidated mice harbor a significant decrease of autophagosome markers (LC3 puncta and p62 aggregates), significant accumulation of $\mathrm{p} 53$ and activated caspase-3. These alterations of pancreatic functions subsequently drive to a diabetic phenotype (increased glucose and fructosamine).

In the Kras-driven PanIN model (Pdx1-Cre; LstopL-K-ras $^{612 D}$ ), the mosaic loss of Atg5 or Atg7 expression leads to an enhanced accumulation of early PanIN (PanIN1A/B) that scarcely progress to later-grade PanIN (PanIN2/3) during the entire lifespan of the mouse (up to 500 days). This could be explained by the sustained expression of p53 that induces growth arrest and cellular senescence and acts as a barrier to the progression of PanINs to PDAC.

It is estimated that about $50 \%$ of PDAC cases are associated with the loss of p53. It was previously shown that concomitant endogenous expression of $\operatorname{Trp} 53^{\mathrm{R} 172 \mathrm{H}}$ and $\mathrm{Kras}^{\mathrm{G} 12 \mathrm{D}}$ leads to development of invasive and widely metastatic adenocarcinoma and thus to a dramatically shortened median survival (Hingorani et al., 2005).

Complex transgenic mice displaying Pdx1-Cre; LstopL-K-ras ${ }^{G 12 D} ; \mathrm{p} 53^{-1-} ; A \operatorname{tg} 7^{\text {flox/flox }} \operatorname{orAtg} 5^{\text {flox/flox }}$ were generated. The genetic conditional invalidation of Atg5 or Atg7 and the following autophagy inhibition accelerates PDAC formation in the absence of $p 53$ suggesting that loss of $p 53$ is crucial and dramatically promotes progression from early PanIN lesions toward adenocarcinoma. The inhibition 
Jonckheere, Vincent \& Van Seuningen

of autophagy via hydroxychloroquine, initially reported as beneficial in cancer treatment, promotes similar PDAC acceleration in the absence of p53.

Finally the authors showed that the combined loss of p53 and Atg7 leads to a decreased oxygen consumption, typical of reduced oxygen metabolism. Indeed the loss of autophagy is associated with acidification of extracellular environment. Cell lines derived from $\mathrm{p} 53^{---}$; Atg $7^{\mathrm{KO}}$ pancreatic tumors revealed an increase of intracellular glucose, glycolytic and pentose phosphate pathway intermediates indicating an enrichment of anabolic pathway that can fuel the tumor growth.

This outstanding analysis is contradictory to previous work performed in vitro by Yang et al who showed that autophagy inhibition in PDAC cell lines attenuates growth and tumorigenicity of xenografted tumors (Yang et al., 2011). In this particular study, the same K-ras driven mouse model was treated with chloroquinine, blocking lysosomal acidification and autophagosome degradation, following the establishment of advanced PanINs or focal PDAC. The authors observed a significant improvement of overall survival. This observation was consistent with Rosenfeldt's findings showing that loss of autophagy leads to accumulation of low grade PanIN and slows down the carcinogenetic progression but did not take into account the extreme importance of p53 status.

Pancreatic adenocarcinoma (PDAC) is one of the most deadly cancers with an extremely poor prognosis notably because of a lack of efficient therapeutic tools (Vincent et al., 2011). Autophagy inhibition that is commonly used in other pathologies (as anti-malarial therapies or for rheumatologic conditions) was thought as a promising therapeutic strategy. However, the discrepancy between these two studies suggests that caution shall be kept regarding autophagy inhibition in pancreatic cancer. There is an urgent need to further explain the dichotomy between observations in human cancer cell lines and mouse preclinical model before even considering hydroxychloroquine or similar molecules as a bona fide therapeutic tool for pancreatic cancer patients. 
Jonckheere, Vincent \& Van Seuningen

\section{Acknowledgments}

This work is supported by Inserm and by SIRIC ONCOLille, Grant INCaDGOS-Inserm 6041. Dr Vincent is the recipient of a postdoctoral fellowship from the Fondation ARC.

\section{References}

Hingorani, SR, Wang, L, Multani, AS, Combs, C, Deramaudt, TB, Hruban, RH, Rustgi, AK, Chang, S \& Tuveson, DA (2005) Trp53R172H and KrasG12D cooperate to promote chromosomal instability and widely metastatic pancreatic ductal adenocarcinoma in mice. Cancer Cell 7, 469-83.

Levine, B \& Kroemer, G (2008) Autophagy in the pathogenesis of disease. Cell 132, 27-42.

Rosenfeldt, MT, O'Prey, J, Morton, JP, Nixon, C, Mackay, G, Mrowinska, A, Au, A, Rai, TS, Zheng, L, Ridgway, R, Adams, PD, Anderson, KI, Gottlieb, E, Sansom, OJ \& Ryan, KM (2013) p53 status determines the role of autophagy in pancreatic tumour development. Nature 504, 296-300.

Vincent, A, Herman, J, Schulick, R, Hruban, RH \& Goggins, M (2011) Pancreatic cancer. Lancet 378, 607-20.

Yang, S, Wang, X, Contino, G, Liesa, M, Sahin, E, Ying, H, Bause, A, Li, Y, Stommel, JM, Dell'antonio, G, Mautner, J, Tonon, G, Haigis, M, Shirihai, OS, Doglioni, C, Bardeesy, N \& Kimmelman, AC (2011) Pancreatic cancers require autophagy for tumor growth. Genes Dev 25, 717-29.

\section{Figure legend}

Figure 1: Loss of autophagy profoundly alters pancreatic homeostasis (A) or carcinogenesis (B) in genetically modified mouse model of pancreatic ductal adenocarcinoma (Pdx1-Cre; LstopL-Kras ${ }^{612 D}$; $\mathrm{p} 53^{-/-} ; \operatorname{Atg} 5^{\text {flox/flox }}$ or $\left.\operatorname{Atg} 7^{\text {flox/flox }}\right)$ 
Physiological autophagy

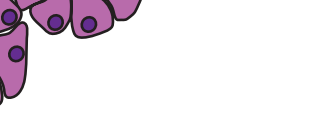

Pancreas
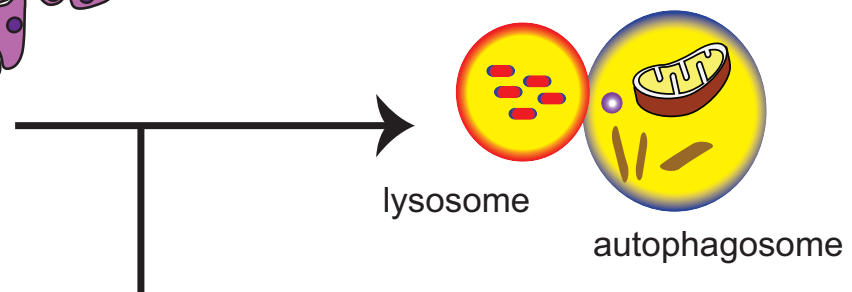

Atg5/7 invalidation

Loss of autophagy lysosome

autophagosome

Pancreas homeostasis

- amino and fatty acids recycling

Pancreas degradation

- reduced survival

- p53 accumulation

- diabetic phenotype

- PanIN1/2/3 lesions

- occasional PDAC

- p53 accumulation mouse model

Pdx1-Cre; KrasG12D

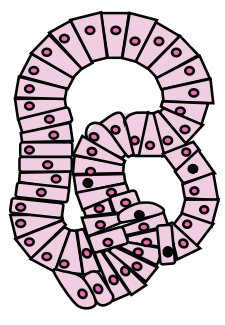

Atg5/7 invalidation

or chloroquine

+ loss of p53

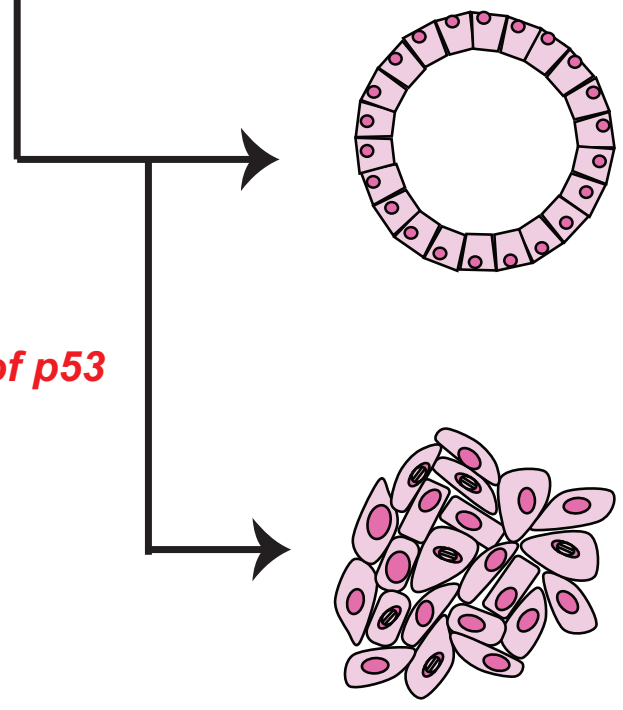

- accumulation of early PanIN1 lesions

- p53 accumulation

- accelerated PDAC formation

- diminished oxydative metabolism

- enhanced glycolysis 